\section{FRI0521 SECUKINUMAB PROVIDES SUSTAINED IMPROVEMENTS IN WORK PRODUCTIVITY AND HEALTH RELATED QUALITY OF LIFE IN PATIENTS WITH ACTIVE PSORIATIC ARTHRITIS: 2-YEAR RESULTS FROM FUTURE 1 AND FUTURE 2}

V. Strand ${ }^{1}$, O. FitzGerald ${ }^{2}$, L.C. Coates ${ }^{3}$, J.A. Walsh ${ }^{4}$, J.D. Cañete ${ }^{5}$, V. Bhosekar ${ }^{6}$, L. Pricop ${ }^{7}$, K. Gandhi ${ }^{7}$, S. Jugl ${ }^{8} .{ }^{1}$ Stanford University School of Medicine, Palo Alto, CA, United States; ${ }^{2}$ St. Vincent's University Hospital, Dublin, Ireland; ${ }^{3}$ University of Leeds, Leeds, United Kingdom; ${ }^{4}$ University of Utah, Salt Lake City, United States; ${ }^{5}$ Hospital Clinic de Barcelona e IDIBAPS, Barcelona, Spain; ${ }^{6}$ Novartis Healthcare, Hyderabad, India; ${ }^{7}$ Novartis Pharmaceuticals Corporation, East Hanover, NJ, United States; ${ }^{8}$ Novartis Pharma AG, Basel, Switzerland

Background: Patients (pts) with PsA experience significant impairment of work productivity (WP) and health-related QoL (HRQoL). Secukinumab (SEC) has previously been shown to rapidly improve symptoms, physical function and HRQoL in pts with active PsA. ${ }^{1,2}$

Objectives: To assess the impact of SEC on WP and HRQoL through 2 years (yrs) in TNF inhibitor (TNF)-naïve PsA pts and those with an inadequate response or intolerance to TNF inhibitors (TNF-IR).

Methods: 606 and 397 pts were randomized to SEC or placebo (PBO) in FUTURE 1 (10 mg/kg IV followed by 150 or $75 \mathrm{mg} \mathrm{SC}$ ) and FUTURE 2 $(300,150$ or $75 \mathrm{mg} \mathrm{SC})$, respectively. PBO pts were re-randomized to SEC at Wk 16/24. WP was assessed using the WP and Activity Impairment-General Health (WPAI-GH) questionnaire. WPAI-GH includes 6 questions to measure absenteeism, presenteeism, work productivity and impairments in unpaid activity because of health problems during the preceding 7 days. HRQoL was assessed using the PsAQoL questionnaire, encompassing 20 statements that pts rate as true or false on the day of completion. Across both trials, approximately $68 \%$ of pts were TNF-naïve and $32 \%$ were TNF-IR. Observed data are presented from the full analysis set and in subgroups stratified by prior TNF exposure. Only data with approved doses of SEC (300 and $150 \mathrm{mg}$ ) are shown.

Results: In FUTURE 1, 88 of 202 in the SEC $150 \mathrm{mg}$ group were employed and working at baseline (BL); 61 of 100 and 59 of 100 were employed and working at BL in the SEC $300 \mathrm{mg}$ and $150 \mathrm{mg}$ groups of FUTURE 2, respectively. Improvements in all elements of WPAI were reported with SEC 300 and 150 $\mathrm{mg}$ in the overall population at Wk 16; responses were sustained through Wk

Table, WPAJ-GH and PsACoL outcomes in FUTURE 1 and FUTURE 2 through Woek 104

\begin{tabular}{|c|c|c|c|c|c|c|c|c|c|}
\hline & \multicolumn{3}{|c|}{ FUTURE 1} & \multicolumn{6}{|c|}{ FUTURE 2} \\
\hline & \multirow{3}{*}{$\begin{array}{c}\text { Overall } \\
\text { seC } \\
\text { IV-15o } \\
\mathbf{m g}\end{array}$} & \multirow{3}{*}{$\begin{array}{c}\text { TNF: } \\
\text { naive } \\
\text { SEC } \\
\text { IV-150 } \\
\text { mg }\end{array}$} & \multirow{3}{*}{$\begin{array}{c}\text { TNF-IR } \\
\text { SEC } \\
\text { IV-1S0 } \\
\text { mg }\end{array}$} & \multicolumn{2}{|c|}{ Overall } & \multicolumn{2}{|c|}{ TNF-naivo } & \multicolumn{2}{|c|}{ TNF $\rightarrow R$} \\
\hline & & & & sec & sec & sec & sec & $\sec$ & SEC \\
\hline & & & & $\begin{array}{l}300 \\
m g\end{array}$ & $\begin{array}{l}150 \\
m g\end{array}$ & $\begin{array}{l}300 \\
m_{g}\end{array}$ & $\begin{array}{l}150 \\
m g\end{array}$ & $\begin{array}{l}300 \\
m g\end{array}$ & $\begin{array}{l}150 \\
m_{g}\end{array}$ \\
\hline \multicolumn{10}{|c|}{ WPAI GH (change from BL) } \\
\hline \multicolumn{10}{|c|}{ Absenteeism (\$ work time miksed due to hearth) ${ }^{F}$} \\
\hline Wk 52 & $\begin{array}{c}-40 \\
(n=77)\end{array}$ & $\begin{array}{c}-5.9 \\
(n=59)\end{array}$ & $\begin{array}{c}2.3 \\
(n=18)\end{array}$ & $\begin{array}{c}-23 \\
(n=48)\end{array}$ & $\begin{array}{c}-8.2 \\
\langle n=51\rangle\end{array}$ & $\begin{array}{c}-3.4 \\
\langle n=37\rangle\end{array}$ & $\begin{array}{c}-7.8 \\
(n=34)\end{array}$ & $\begin{array}{c}13 \\
(n=11)\end{array}$ & $\begin{array}{c}-6.9 \\
(n=17)\end{array}$ \\
\hline Wk 104 & $\begin{array}{c}-2.9 \\
(n=58)\end{array}$ & $\begin{array}{c}-24 \\
(n=46)\end{array}$ & $\begin{array}{c}-49 \\
(n=12)\end{array}$ & $\underset{(n=45)}{-0,4}$ & $\begin{array}{c}-68 \\
(n=41)\end{array}$ & $\begin{array}{c}-1.1 \\
(n \times 34)\end{array}$ & $\begin{array}{c}-6.8 \\
(n=30)\end{array}$ & $\begin{array}{c}15 \\
\text { (n=t1) }\end{array}$ & $\begin{array}{l}-6.7 \\
\text { (n=11) }\end{array}$ \\
\hline \multicolumn{10}{|c|}{ Presenteeism (\$ impairment while working due to health)" } \\
\hline Wk 52 & $\begin{array}{l}-13.4 \\
(n=73)\end{array}$ & $\begin{array}{l}-162 \\
\text { (no5s) }\end{array}$ & $\begin{array}{c}-50 \\
(n=18)\end{array}$ & $\begin{array}{c}-16.7 \\
(n=49)\end{array}$ & $\begin{array}{c}-182 \\
(n=49)\end{array}$ & $\begin{array}{l}-18.2 \\
(n=36)\end{array}$ & $\begin{array}{l}-11.9 \\
(n=32)\end{array}$ & $\begin{array}{l}-11.8 \\
(n=11)\end{array}$ & $\begin{array}{l}-30.0 \\
(n=17)\end{array}$ \\
\hline Wh 104 & $\begin{array}{l}-10.0 \\
(\mathrm{n}=55)\end{array}$ & $\begin{array}{l}-10.7 \\
(\text { ma43) }\end{array}$ & $\begin{array}{l}-7.5 \\
(0=12)\end{array}$ & $\begin{array}{l}-14.4 \\
\text { (n } 246)\end{array}$ & $\begin{array}{c}-16.8 \\
(n=38)\end{array}$ & $\begin{array}{l}-16.9 \\
(n<36)\end{array}$ & $\begin{array}{l}-10.7 \\
(n=27)\end{array}$ & $\begin{array}{c}-5.0 \\
(n=10)\end{array}$ & $\begin{array}{l}-31,8 \\
(n=11)\end{array}$ \\
\hline \multicolumn{10}{|c|}{ Work Productivity (\% overall work impsirment due to health) } \\
\hline Wk 52 & $\begin{array}{l}-15.8 \\
(n+71)\end{array}$ & $\begin{array}{l}-18.5 \\
\text { (nus5) }\end{array}$ & $\begin{array}{c}-6.3 \\
(n=16)\end{array}$ & $\begin{array}{c}-16.3 \\
(n=48)\end{array}$ & $\begin{array}{c}-18.3 \\
\langle n=48\rangle\end{array}$ & $\begin{array}{l}-18, \\
(n=37)\end{array}$ & $\begin{array}{l}-11,5 \\
(n=31)\end{array}$ & $\begin{array}{c}-9.4 \\
\text { (n=11) }\end{array}$ & $\begin{array}{l}-30.6 \\
(n=17)\end{array}$ \\
\hline Wk 104 & $\begin{array}{l}-10.3 \\
\text { (nass) }\end{array}$ & $\begin{array}{l}-11.3 \\
(p=44)\end{array}$ & $\begin{array}{c}-6.2 \\
\text { (ne11) }\end{array}$ & $\begin{array}{l}-11.2 \\
(n=24)\end{array}$ & $\begin{array}{c}-16.8 \\
\langle\mathrm{n}=37\rangle\end{array}$ & $\begin{array}{l}-16.0 \\
(n=34)\end{array}$ & $\begin{array}{c}-9.4 \\
\{n=26\}\end{array}$ & $\begin{array}{c}-1.8 \\
\{n=10\}\end{array}$ & $\begin{array}{l}-34.1 \\
(n=11)\end{array}$ \\
\hline \multicolumn{10}{|c|}{ Activity Impairment (K activity impsirment due to health) $)^{2}$} \\
\hline Wk 52 & $\begin{array}{c}-14.9 \\
(n+174)\end{array}$ & $\begin{array}{l}-14.8 \\
(p=126)\end{array}$ & $\begin{array}{l}-15.2 \\
(n * 48)\end{array}$ & $\begin{array}{c}-20.0 \\
(n=92)\end{array}$ & $\begin{array}{c}-22.1 \\
\langle n=89\rangle\end{array}$ & $\begin{array}{l}-20.7 \\
(n=61)\end{array}$ & $\begin{array}{l}-23.1 \\
(n=5 \theta)\end{array}$ & $\begin{array}{l}-18.7 \\
\text { (n=31) }\end{array}$ & $\begin{array}{l}-20.3 \\
(n=30)\end{array}$ \\
\hline Wh 104 & $\begin{array}{c}-14,1 \\
(n=143)\end{array}$ & $\begin{array}{l}-122 \\
(n=107)\end{array}$ & $\begin{array}{l}-20.0 \\
(0-36)\end{array}$ & $\begin{array}{c}-17.7 \\
(n=84)\end{array}$ & $\begin{array}{l}-18.5 \\
(n \times 78)\end{array}$ & $\begin{array}{l}-19.7 \\
\langle n=57\rangle\end{array}$ & $\begin{array}{l}-19.8 \\
(n=52)\end{array}$ & $\begin{array}{l}-13.7 \\
(n-27)\end{array}$ & $\begin{array}{l}-15.8 \\
(n-26)\end{array}$ \\
\hline \multicolumn{10}{|c|}{ PsACOL (change from BL) ${ }^{C T}$} \\
\hline Wk 52 & $\begin{array}{c}-40 \\
(n-181)\end{array}$ & $\begin{array}{c}-4,1 \\
(p=130)\end{array}$ & $\begin{array}{c}-3.6 \\
\text { (n-51) }\end{array}$ & $\begin{array}{c}-A, 1 \\
\text { (n=24) }\end{array}$ & $\begin{array}{c}-5.2 \\
(n=88)\end{array}$ & $\begin{array}{c}-4.0 \\
(n=62)\end{array}$ & $\begin{array}{c}-5.6 \\
\text { (n-58) }\end{array}$ & $\begin{array}{c}-4 / 4 \\
(n=32)\end{array}$ & $\begin{array}{c}-4 / 4 \\
(n+30)\end{array}$ \\
\hline wh 104 & $\begin{array}{c}-38 \\
(n=149)\end{array}$ & $\begin{array}{c}-3.6 \\
(n=110)\end{array}$ & $\begin{array}{c}-4.4 \\
(n+39)\end{array}$ & $\begin{array}{c}-4.6 \\
\text { (n } n=86)\end{array}$ & $\begin{array}{c}-5.6 \\
(n=76)\end{array}$ & $\begin{array}{c}-4.4 \\
(n=57)\end{array}$ & $\begin{array}{c}-5.6 \\
(n=52)\end{array}$ & $\begin{array}{c}-4.9 \\
(n=29)\end{array}$ & $\begin{array}{l}-5.6 \\
(n=24)\end{array}$ \\
\hline
\end{tabular}

104 (Table). The greatest improvements were seen in presenteeism $(-10.0)$, work productivity $(-10.3)$ and activity impairment $(-14.1)$, which corresponded to improvements from BL of approximately $29 \%, 26 \%$ and $30 \%$, respectively in the overall population of FUTURE 1 at Wk 104; similar improvements were seen in FUTURE 2 at Wk 104 (300 mg: -14.4 [42\%], -11.2 [33\%] and -17.7 [38\%]; $150 \mathrm{mg}:-16.8$ [50\%], -16.8 [45\%] and -18.5 [38\%]). Sustained improvements in all elements of WPAI were also evident with SEC in TNF-naïve and TNF-IR pts in both FUTURE 1 and FUTURE 2. Improvements in PSAQoL were reported as early as Wk 4 and sustained through Wk 104. At Wk 104 of FUTURE 2, PsAQoL scores had improved by approximately $46 \%$ from BL with SEC $300 \mathrm{mg}$ and $49 \%$ with SEC $150 \mathrm{mg}$ in the overall population. Similar improvements were seen in TNF-naïve (47\% and 51\%, respectively) and TNF-IR pts (45\% and $45 \%$, respectively). Consistent results were reported in FUTURE 1. The efficacy of SEC was consistent regardless of concomitant MTX use.

Conclusions: SEC provided sustained improvements in WP and PSAQoL in pts with PsA for up to 104 wks, regardless of prior TNF exposure.

\section{References:}

[1] McInnes. Lancet 2015;386:1137-46.

[2] Mease. NEJM 2015;373:1329-39.

Disclosure of Interest: V. Strand Consultant for: AbbVie, Amgen, BMS, Celgene, Celltrion, CORRONA, Genentech/Roche, GSK, Janssen, Lilly, Merck, Novartis, Pfizer, Regeneron, Samsung, Sanofi, and UCB, O. FitzGerald Grant/research support from: Abbvie, BMS, Celgene, Janssen, MSD, Novartis, Pfizer, Sun Pharma, UCB, L. Coates Grant/research support from: Abbvie, BMS, Celgene, Janssen, Lilly, MSD, Novartis, Pfizer, Sun Pharma, UCB, J. Walsh Consultant for: Novartis, J. Cañete Consultant for: AbbVie, Boehringer Ingelheim, Celgene, Janssen, Lilly, Novartis, V. Bhosekar Employee of: Novartis, L. Pricop Employee of: Novartis, K. Gandhi Shareholder of: Novartis, Employee of: Novartis, S. Jugl Shareholder of: Novartis, Employee of: Novartis

DOI: 10.1136/annrheumdis-2017-eular.1832

\section{FRI0522 THE ASSOCIATION BETWEEN OCCUPATIONAL-RELATED MECHANICAL STRESS AND RADIOGRAPHIC DAMAGE IN PSORIATIC ARTHRITIS}

W. Zhou ${ }^{1}$, R. Cook ${ }^{2}$, V. Chandran ${ }^{1,3}$, D.D. Gladman ${ }^{1,3}$, L. Eder ${ }^{1,4}{ }^{1}{ }^{1}$ Department of Medicine, University of Toronto, Toronto; ${ }^{2}$ Department of Statistics and Actuarial Science, University of Waterloo, Waterloo; ${ }^{3}$ Centre for Prognosis Studies in the Rheumatic Diseases, University Health Network; ${ }^{4}$ Women's College Research Institute, Women's College Hospital, Toronto, Canada

Background: Mechanical stress is thought to play a role in the development of psoriatic arthritis (PsA).

Objectives: To determine the association between occupational-related mechanical factors and the severity of radiographic peripheral and axial joint damage in patients with PsA

Methods: A retrospective cohort study was conducted in patients with longstanding PsA (>10 years duration). Patients were asked to report all paid employment since the age of 18 . The key predictor variables included various occupational-related mechanical exposures. For each job, the Occupational Information Network ( $\mathrm{O}^{*} \mathrm{NET}$ ) was used to rate the level of exposure to 11 workers abilities and 16 occupational exposures. The outcomes of interest were the extent of radiographic damage in the peripheral and axial joints, as measured by the modified Steinbrocker score (mSS), and the modified Stokes Ankylosing Spondylitis Spine Score (mSASSS). The association between the predictor and outcome variables was assessed by linear multivariable regression models after adjusting for age, sex, PsA duration and lifestyle habits.

Results: 307 eligible patients were analyzed. Univariate analysis identified severeal occupational factors associated with radiographic damage (Table 1-2). In the multivariable regression analysis prolonged repetitive hand movements Table 1. Linear Regression Analysis - The association between high level of work-related exposure and modified Steinbrocker score

\begin{tabular}{lccccc}
\hline Exposure & \multicolumn{2}{c}{ Univariate analysis } & & \multicolumn{2}{c}{ Multivariable Reduced Model $^{*}$} \\
\cline { 2 - 3 } & $\beta(95 \% \mathrm{Cl})$ & $\mathrm{P}$ value & & $\beta(95 \% \mathrm{Cl})$ & $\mathrm{P}$ value \\
\hline Sitting & $-15.7(-29.2,-2.3)$ & 0.02 & & $-11.9(-25.4,1.6)$ & $\mathbf{0 . 0 8 5}$ \\
Hands handle & $23.1(4.4,42)$ & $\mathbf{0 . 0 2}$ & & & \\
Repetitive hands motions & $33(11.7,54.4)$ & 0.002 & & $29.5(8.2,50.8)$ & $\mathbf{0 . 0 0 7}$ \\
Twisting/Bending & $18.8(1.4,36.2)$ & 0.03 & & \\
Minor burns & $21.5(2.7,40.4)$ & 0.03 & & \\
Awkward body position & $17.7(-1.1,36.5)$ & 0.06 & & \\
\hline
\end{tabular}

Table 2. Linear Regression analysis - The association between workers' abilities and modified Steinbrocker score

\begin{tabular}{lccccc}
\hline Exposure & \multicolumn{2}{c}{ Univariate analysis } & & \multicolumn{2}{c}{ Multivariable Reduced Model $^{*}$} \\
\cline { 2 - 3 } & $\beta(95 \% \mathrm{Cl})$ & $\mathrm{P}$ value & & $\beta(95 \% \mathrm{Cl})$ & $\mathrm{P}$ value \\
\hline Manual dexterity & $2.5(0.4,4.6)$ & 0.02 & & \\
Arm-hand steadiness & $2.7(0.6,5.0)$ & 0.01 & & \\
Finger dexterity & $5.3(1.4,9.2)$ & 0.008 & & $5.4(1.6,9.2)$ & 0.005 \\
Trunk strength & $2.0(-0.3,4.4)$ & 0.09 & & \\
Wrist-finger speed & $3.2(-0.4,6.8)$ & 0.08 & & \\
Extent flexibility & $1.9(-0.3,4.2)$ & 0.10 & &
\end{tabular}

"Each model was adjusted for age, sex, duration of PsA, smoking, BMI, Biologics therapy (ever), DMARDs therapy (ever). 
was associated with a higher peripheral joint damage score (by mSS, adjusted $\beta=29.5,95 \% \mathrm{Cl} 8.2,50.8, p=0.007$, Table 1 ), while the association between prolonged time spent sitting and lower mSS was of borderline significance $(p=0.085$, Table 1$)$. Additionally, occupations that required higher finger dexterity were associated with higher $\mathrm{mSS}$ (adjusted $\beta=5.4,95 \% \mathrm{Cl} 1.6,9.2, p=0.005$, Table 2). Regarding axial damage, occupations that involved prolonged walking/running were associated with a higher mSASSS score (adjusted $\beta=4.4,95 \% \mathrm{Cl} 0.1,8.7$, $p=0.04$ ). PsA duration was independently associated with both peripheral and axial joint damage $(\mathrm{p}<0.001)$.

Conclusions: High level of occupation-related mechanical stress is associated with increased radiographic peripheral joint damage. These findings support the potential role of micro-trauma in the pathogenesis of PsA.

Disclosure of Interest: None declared

DOI: 10.1136/annrheumdis-2017-eular.4074

\section{FRI0523 SHORT-TERM EFFICACY AND SAFETY OF NEW BIOLOGICAL AGENTS TARGETING THE IL-6, IL-12/23 AND IL-17 PATHWAYS FOR ACTIVE PSORIATIC ARTHRITIS: A NETWORK META-ANALYSIS OF RANDOMISED CONTROLLED TRIALS}

W. Dongze, Y. Jiang, L.-S. Tam. Department of Medicine \& Therapeutics, The Prince of Wales Hospital, the Chinese University of Hong Kong, Hong Kong, China

Background: IL-6, IL-12/23 and IL-17 inhibitors have been found to be highly effective for both skin and joint manifestations of psoriatic arthritis (PsA). Nonetheless, reliable evidence of the comparative benefits and harms for these interventions is absent for treatment selection in daily practice.

Objectives: To investigate the comparative efficacy, safety and tolerability of IL-6, IL-12/23 or IL-17 inhibitors and the proportion attributable to overall treatment for patients with active PsA.

Methods: Randomized controlled trials (RCTs) evaluating the efficacy, safety and tolerability of IL-6, IL12/23 or IL17 inhibitors at weeks 24 were identified by a comprehensive systematic literature review (PROSPERO 2016: CRD42016048166). Quality of evidence was assessed following the Grading of Recommendations, Assessment, Development and Evaluations (GRADE) approach. Treatment effects were evaluated based on the intention-to treat efficacy rates (ACR20, ACR50), safety parameters (any adverse effect [AE], serious adverse effect [SAE]) and tolerability (discontinuation due to AE [DAE]). Pair-wise meta-analyses and Bayesian network meta-analyses using the random-effects model were performed to estimate pooled odds ratios (ORs) and 95\% credible interval ( $\mathrm{Crl}$ ). A subgroup analysis was performed to investigate the effects of prior anti-TNF exposure on the efficacy of ustekinumab and secukinumab.

Results: Six trials were identified which included 2411 participants and 11 treatments. All trials were of generally high quality according to Cochrane compliant rules and GRADEpro assessment. Direct comparisons of each biologic showed that secukinumab, ustekinumab and ixekizumab demonstrated superior efficacy over placebo with respect to all efficacy outcomes (ACR20 and ACR50). Regarding safety and tolerability, ixekizumab has a higher incidence of adverse events while ustekinumab were more tolerable compared with placebo. Mixed treatment comparisons showed that secukinumab (300mg monthly) had the highest efficacy in achieving ACR20 and ACR50; whereas clazakizumab (200mg monthly), ustekinumab (45mg 12 weekly), secukinumab (150mg monthly) had the lowest probability of having $\mathrm{AE}, \mathrm{SAE}, \mathrm{DAE}$, respectively. Considering the overall risk-benefit profile of IL-6, IL12/23, IL17 inhibitors in the treatment of active PsA, secukinumab (150mg monthly) may offer an optimal balance for active PsA patients (Figure 1). When considering ACR 20 response, subgroup analysis revealed that anti-TNF naïve patient respond significantly better than placebo for all dosages of secukinumab and ustekinumab used. In contrast, only higher dose of secukinumab and ustekinumab were significantly more effective than placebo in anti-TNF failure patient.

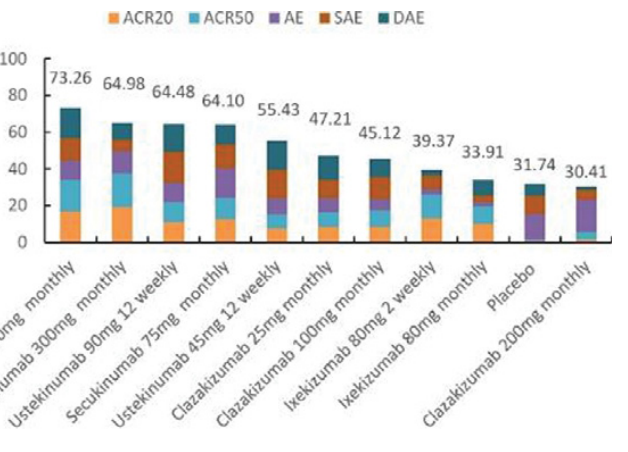

Figure 1

Conclusions: In conclusion, from the available evidence, secukinumab and ustekinumab were found to be the safest and most efficacious short-term treatments for active PsA amongst all the new biologics targeting the IL-6, IL-12.23 and IL-17 pathways.

Acknowledgements: Thank all colleagues working in the Division of Rheuma- tology, Department of Medicine and Therapeutics, The Prince of Wales Hospital, The Chinese University of Hong Kong.

Disclosure of Interest: None declared

DOI: 10.1136/annrheumdis-2017-eular.1469

\section{FRIDAY, 16 JUNE 2017} Osteoporosis

\section{FRI0524 CAROTID ATHEROSCLEROSIS IS ASSOCIATED WITH COMPROMISED VOLUMETRIC BONE MINERAL DENSITY AND MICROSTRUCTURES IN PATIENTS WITH INFLAMMATORY} ARTHRITIS

T.H. Cheng ${ }^{1}$, Q. Shang ${ }^{1}$, E.K.M. Li ${ }^{1}$, P.C.H. Wong ${ }^{1}$, E.W.L. Kun ${ }^{2}$, M. Li ${ }^{1}$, T.K.Y. Li ${ }^{1}$, T.Y. Zhu ${ }^{3}$, A.P.W. Lee ${ }^{1}$, L. Qin ${ }^{3}$, L.S. Tam ${ }^{1} .{ }^{1}$ Department of Medicine and Therapeutics, the Chinese University of Hong Kong; ${ }^{2}$ Department of Medicine \& Geriatrics, Tai Po Hospital; ${ }^{3}$ Department of Orthopaedics and Traumatology, the Chinese University of Hong Kong, Hong Kong, Hong Kong

Background: Carotid Atherosclerosis is associated with compromised volumetric bone mineral density and microstructures in patients with inflammatory arthritis

Objectives: The aim of this study was to explore the relationship between volumetric bone mineral density (VBMD)/microstructural features and presence of carotid plaque $(\mathrm{CP})$ in patients with inflammatory arthritis.

Methods: 175 inflammatory arthritis patients (81 [46\%] PsA, 94 [54\%] RA; 70 [40\%] males; age: $53 \pm 12$ years) were recruited into an ongoing prospective study assessing the relationship between inflammation, osteoporosis and carotid atherosclerosis. Carotid plaque and intima-media thickness (IMT) were measured by carotid ultrasound. Areal BMD (aBMD) was measured by dual energy X-ray absorptiometry (DXA). Microstructure features and vBMD of distal radius were measured using high-resolution peripheral quantitative computed tomography (HR-pQCT).

Results: No patients had established cardiovascular disease (CVD). Data from 172 patients at baseline were analyzed for this cross-sectional study. Patients were sub grouped according to the presence or absence of carotid plaque (CP+ group, $n=68[40 \%]$ ) and CP-group, $n=132$ [60\%]). CP+ group were older ( $59 \pm 10$ vs $49 \pm 11, p<0.001)$, more likely to be male ( $54 \%$ vs $31 \%, p=0.002)$, had higher systolic blood pressure ( $130 \pm 19$ vs $124 \pm 17 \mathrm{mmHg}, p=0.034)$ and CVD risk $(15.7 \pm 14.2$ vs $7.9 \pm 8.6, p<0.001)$ according to the Framingham Risk Score (FRS) then the CP- group. aBMD, vBMD and microstructure were significantly compromised in the $\mathrm{CP}+$ group. Distal radius $\mathrm{aBMD}$, distal radius total VBMD, trabecular (Tb) vBMD, Tb thickness, cortical (Ct.) vBMD, Ct. thickness and bone volume fraction were $5 \%(p=0.004), 12 \%(p<0.001), 8 \%(p=0.007), 8 \%(p=0.004)$, $4 \%(p=0.007), 10 \%(p=0.001)$ and $8 \%(p=0.007)$ lower in the $C P+$ group. The differences remained significant after adjustment for gender, disease type and FRS (Table 1).

Table - Distal radius $\mathrm{VBMD} /$ microstructure and presence of plaque

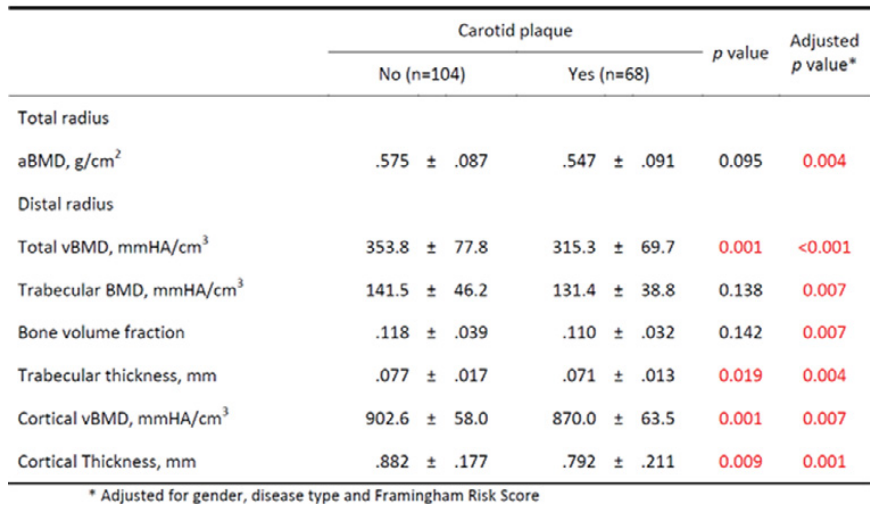

Conclusions: Inflammatory arthritis patients with carotid plaque had lower aBMD, vBMD and compromised bone microstructure in the distal radius even after adjustment for gender, disease type and FRS, suggesting that inflammation may be the common link for both conditions.

Disclosure of Interest: None declared

DOI: 10.1136/annrheumdis-2017-eular.3094 